\title{
IDENTIFIKASI TINGKAT KENYAMANAN LINGKUNGAN KERJA FISIK PADA CHEFBURJO BORNEO TERHADAP SUHU UDARA
}

\author{
Inaaratul Chusna Ichda Puwanto, Aldi Yoga Pradana, Alex Alfandianto \\ Program Studi Teknik Industri, Fakultas Sains dan Teknologi, \\ Universitas Teknologi Yogyakarta \\ chusnanaara@gmail.com,aldiyogapradana98@gmail.com,alexalfandianto@gmail.com
}

\begin{abstract}
In general, people spend more than $90 \%$ of the time in the room, so they need a comfortable air in the space where they move, therefore the good indoor air velocity is very beneficial to them. Resolving indoor comfort issues is possible through a thorough research based on the air velocity in the cooking room. The analysis of the physical work environment of the cooking room of Burjo Borneo, the researcher will give the output or the result of the relationship of air temperature influence to the convenience of cooking operator, therefore, work and effort can be done to cooking operator to cook and serve food, the negative impacts arising from the problem. Air temperature to comfort level, it is known that the minimum temperature with an average of $29.30^{\circ} \mathrm{C}$ and a maximum temperature of $30,50^{\circ} \mathrm{C}$ gives the amount of discomfort much higher than the air quality level. This is because during breaks to cook and serve food, cooking operators hard to concentrate on doing activities. It was found that the factors of discomfort and the temperature of the hot air into the treatment that caused the feeling uncomfortable. This is because in hot temperatures, cooking operators experience rapid sweat excretion.
\end{abstract}

Keywords: Physical, Working, Environment, Air, Temperature

\begin{abstract}
Abstrak
Pada umumnya orang menghabiskan waktunya lebih dari 90\% di dalam ruangan, sehingga mereka membutuhkan udara yang nyaman dalam ruang tempat mereka beraktivitas, oleh karenanya kecepatan udara yang baik dalam ruangan sangat bermanfaat bagi mereka. Penyelesaian masalah kenyamanan dalam ruangan dimungkinkan melalui penelitian menyeluruh berdasarkan kecepatan udara di dalam ruangan cooking. Analisis dari lingkungan kerja fisik di ruang cooking Burjo Borneo, yang nantinya peneliti akan memberikan output ataupun hasil hubungan pengaruh suhu udara terhadap kenyamanan cooking operator, maka dari itu, kerja dan upaya yang dapat dilakukan agar cooking operator untuk masak dan menyajikan makanan,sehingga dapat mengendalikan berbagai dampak negatif yang timbul akibat masalah tersebut. Suhu udara terhadap tingkat kenyamanan, diketahui bahwa suhu minimal dengan rata-rata $29,3^{\circ} \mathrm{C}$ dan suhu maksimal $30,5^{\circ} \mathrm{C}$ memberikan jumlah ketidaknyamanan jauh lebih tinggi dari pada tingkat kualitas udara. Hal ini disebabkan karena saat istirahat untuk masak dan menyajikan makanan, cooking operator susah berkonsentrasi dalam melakukan aktivitas. Didapatkan bahwa faktor ketidaknyamanan dan faktor suhu udara panas menjadi perlakuan yang menimbulkan merasa tidak nyaman. Hal ini disebabkan karena pada suhu udara yang panas, cooking operator mengalami ekskresi keringat yang pesat.
\end{abstract}

Kata kunci: Lingkungan, Kerja, Fisik, Suhu, Udara

\section{PENDAHULUAN}

Berdasarkan data yang dirilis oleh Badan Meteorologi Klimatologi dan Geofisika (BMKG), temperatur di Indonesia berada di kisaran $23^{\circ} \mathrm{C}$ sampai $34^{\circ} \mathrm{C}$, dengan kelembapan relatif berkisar antara $60 \%$ sampai $95 \%$ pada pagi dan malam hari (BMKG, Desember 2015). Dalam ilmu

ergonomi dikenal paling empat macam kenyamanan, seperti: kenyamanan ruang, kenyamanan penglihatan, kenyamanan pendengaran dan kenyamanan termis. Dalam penelitian ini, penulis akan melakukan penelitian terhadap kenyamanan termis atau suhu udara. Dalam kenyamanan suhu, manusia merasakan sensasi panas atau 
dingin sebagai wujud respon dari sensor perasa pada kulit terhadap stimuli (rangsangan) suhu disekitarnya. Sensor perasa berperan menyampaikan rangsangan rasa kepada otak, dimana otakakan memberikan perintah kepada bagian-bagian tubuh tertentu agar melakukan antisipasi guna mempertahankan suhu tubuh, agar tetap berada pada sekitar $37^{\circ} \mathrm{C}$. Hal ini diperlukan organ tubuh agar dapat menjalankan fungsinya secarabaik.Dari penelitian yang dilakukan bahwa kriteria yang merasakan terhadap suhu disekitar ruang chef burjo borneo, stimuli itu dirasakan mulai dari pukul 07.30 WIB sampai dengan pukul 08.50 WIB. Bahwayang dirasakan sama halnya ketika berada dilapangan yang luas dan terkena sinar matahari langsung. Pada saat itu peneliti telah melakukan penelitian pada pukul 07.30 WIB dengan durasi 10 menit. Saat penelitian dapat dilihat bahwa kualitas udara relatif sehat. Selama10 menit penelitian didapat hasil pengukuran suhu mulai dari suhu standar $29,3^{\circ} \mathrm{C}$ hingga $30,5^{\circ} \mathrm{C}$, dari suhu normal hingga suhu yang paling panas.

Dengan mempertimbangkan seluruh aspek lingkungan kerja fisik yang memiliki potensi bahaya pada kualitas udara ruangan cooker burjo borne yang tidak menyebar secara merata, disamping itu juga, udara yang ada disana juga mempengaruhi ekskresi keringat yang pesat dan badan terasa gerah. Maka kondisi-kondisi bahaya tersebut dapat diantisipasi dan diberi tindakan-tindakan preventif lainnya.Dan akan berpengaruh secara signifikan terhadap hasil kerja dari manusia.

Dari hasil penelitian setiap 10 menit di ruang chefburjo borne tersebut. Dapat disimpulkan bahwa banyak yang mengatakan, nafas terasa sesak, panas, gerah kurang udara bersih, itu efek yang mereka rasakan. Selain itu juga ada merasa kurang nyaman, tidak nyaman bahkan tidak nyaman sekali. Meraka juga memberikan solusi untuk mengatasi masalah ini, beberapa solusinya adalah: diberi kipas angin yang lebih, harus diberi ventilasi, dan tata rungannya di perbaharui lagi.

Pada umumnya orang menghabiskan waktunya (lebih dari 90\%) di dalam ruangan, sehingga mereka membutuhkan udara yang nyaman dalam ruang tempat mereka beraktivitas, oleh karenanya kecepatan udara yang baik dalam ruangan sangat bermanfaat bagi mereka. Penyelesaian masalah kenyamanan dalam ruangan dimungkinkan melalui penyelidikan menyeluruh berdasarkan kecepatan udara di dalam ruangan. Menurut Cheng et al. (2008), bila menggunakan kipas, kisaran suhu yang diperoleh dari investigasi langsung dan tidak langsung masing-masing adalah $28.2^{0}$ $\mathrm{C}$ dan $27.2^{\circ} \mathrm{C}$.

Analisis dari lingkungan kerja fisik di ruang chef burjo borneo, yang nantinya peneliti akan memberikan outputataupun hasil hubungan pengaruh suhu udara terhadap kenyamanan pengunjung kantin, maka dari itu, kerja dan upaya yang dapat dilakukan agar pengunjung nyaman untuk makan dan minum, dan dapat mengendalikan berbagai dampak negative yangtimbul akibat masalah tersebut, sehingga tercipta lingkungan istirahat yang sehat, nyaman, aman dan produktif.

\section{METODE PENELITIAN Jenis Penelitian}

Penelitian dalam studi kasus ini dilakukan dengan menggunakan metode deskriptif, yaitu metode yang bertujuan memberikan penjelasan secara tepat dan sebenarnya mengenai obyek penelitian dalam hal ini adalah penilaian factor lingkungan kerja fisik di ruang chef burjo borneo.

\section{Lokasi Penelitian}

Penelitian dilaksanakan di Ruang Chef Burjo Borneo. Jln. Seturan Raya, No. 403, Condongcatur, Kec. Depok, Yogyakarta, Daerah Istimewa Yogyakarta. Penelitian dilaksanakan selama satu jam, mulai jam $07.50-0.8 .50$ WIB.

\section{Obyek Penelitian}

Penulisan laporan ini di titik beratkan pada penilaian faktor lingkungan kerja fisik di bagian ruang satpam sebagai upaya pencegahan suhu udara yang panas akibat tata ruang yang kurang ergonomis.

\section{Pengumpulan Data}

Kumpulan data-data yang diperoleh dari penelitian berasal dari: 
1. Data Primer Merupakan data langsung dari sumbernya, meliputi :

a. Hasil Observasi di Lapangan

Disebut juga pengamatan, yang dilakukan di bagian ruang kantin untuk mengetahui penilaian factor kerja fisik lingkungan di bagian ruang kerja di ruang chef burjo borneo.

Mengadakan pengukuran intensitas suhu udara dan tingkat kenyamanan di bagian ruang chef burjo borneo.

b. Diskusi

Pembahasan data-data yang telah terkumpul untuk mendapatkan informasi paling akurat.

2. Data Sekunder

Data sekunder adalah data yang diperoleh secara tidak langsung, didapat dari:

a. Data dari dokumen jurnal lain.

Berisi tentang pengukuran-pengukuran faktor kerja fisik lingkungan di berbagi tempat yang pernah diteliti, untuk kemudian dibandingkan dengan peraturan dan penelitian yang ada.

b. Literatur dan referensi

Penulis yang menggali keterangan tertulis dari berbagai wacana dan laporan sebelumnya sebagai dasar pertimbangan.

\section{Instrument Penelitian}

Peralatan yang digunakan dalam penelitian ini adalah:

1. Thermometers

Berfungsi untuk mengukur temperatur udara

a. Bagian-Bagian dari Alat

1. Jam Digital

2. Digital/level meter

3. Selector untuk memilih skala intensitas suhu udara : skala $-20^{\circ} \mathrm{C}-60^{\circ} \mathrm{C}$ dengan jangkauan intensitas Fahreinheit antara $4^{\circ} \mathrm{F}$ sampai $140^{\circ} \mathrm{F}$.

b. Prinsip Kerja Alat

Sebuah level meter/skala yang apabila terkena suhu yang panas akan menghasilkan arus perubahan pada digital level meter sehingga suhu panas tersebut mampu menghidupkan digital. Semakin besar intensitas suhu udara yang terdeteksi, maka semakin besar level meternya sehingga angka pada digital juga besar.

\section{c. Cara Penggunaan Alat}

1. Meletakan termometer diatas meja dari lantai, kemudian dihidupkan "on".

2. Catat level meter setiap ada perubahan sampai layar menunjukkan angka tertinggi, kemudian catat skala setiap menit/perubahan dan diletakkan pada udara yang panas.

3. Membaca hasil dengan melihat angka yang muncul dari suhu standar hingga suhu tertinggi

\section{Analisa Data}

Untuk mengetahui penilaian faktor lingkungan kerja fisik di ruang chefburjo borneo, yaitu melalui penelitian secara langsung dan observasi lingkungan secara langsung. Dengan diperolehnya data yang sudah ada di tempat penelitian. Maka peneliti akan membahasnya secara deskriptif. Hasil yang telah tersedia akan dibahas denganmembandingkan dengan peraturan yang ada maupun dengan teori yang sudah ada.

\section{HASIL DAN PEMBAHASAN Analisis Data Penelitian}

Pengambilan data dilakukan dengan cara memberikan uji perlakuan terhadap performansi suhu udara dan pemberian kuisioner secara langsung, menggunakan kombinasi faktor perlakuan terhadap kondisi lingkungan kerja. Kondisi lingkungan kerja yang menjadi variabel adalah temperatur, tingkat kenyamanan, dan tingkat kualitas udara.

Dari ketiga faktor tersebut dikombinasikan kedalam beberapa perlakuan. Adapun data yang dibutuhkan adalah data pengukuran dan kuisioner darirespon dalam pengaruh kenyamanan pengunjung terhadap suhu udara dikantin. Adapun data yang dibutuhkan dari beberapa kondisi, sebagai berikut:

1. Suhu udara panas

2. Suhu udara kotor

3. Partikel yang bercampur dengan udara

4. Tingkat kualitas udara

\section{Pengolahan dan Analisis Data}

Dalam pengolahan data dilakukan dengan membuat tabel hubungan antara beberapa 
faktor yang telah diteliti terhadap jumlah pengunjung dan dengan menggunakan software microsotf excel dengan menginputkan data tersebut.

Berdasarkan tabel pengaruh kenyamanan terhadap suhu udara, diketahui bahwa suhu panas menghasilkan jumlah ketidak-nyamanan yang juga jauh lebih tinggi dari pada factor lain. Hal ini disebabkan karena adanya tata letak yang kurang efektif, dimana kemampuan pengunjung dalam istirahat untuk makan dan menjadi berpengaruh oleh terhadapa suhu udara yang panas.

\section{Analisis Tabel Penelitian terhadap Suhu Udara}

Analisis tabel penelitian terhadap suhu udara terdiri dari pengaruh pengaruh kondisi terhadap tingkat kenyamanan dan temperature.

Tabel 1. Tabel Hasil Pengukuran Suhu

\begin{tabular}{|c|c|c|c|}
\hline No & $\begin{array}{c}\text { Data } \\
\text { Penelitian }\end{array}$ & $\begin{array}{c}\text { Nilai } \\
\text { Ambang } \\
\text { Batas } \\
\text { (derajat } \\
\text { celcius) }\end{array}$ & Analisis \\
\hline 1 & 29,3 & $20-28$ & $\begin{array}{c}\text { Belum } \\
\text { Terlalu } \\
\text { Panas }\end{array}$ \\
\hline 2 & 30,4 & $20-29$ & $\begin{array}{c}\text { Sedikit Mulai } \\
\text { Panas }\end{array}$ \\
\hline 3 & 30,0 & $20-30$ & $\begin{array}{c}\text { Sedikit Mulai } \\
\text { Panas }\end{array}$ \\
\hline 4 & 30,1 & $20-31$ & $\begin{array}{c}\text { Sedikit Mulai } \\
\text { Panas }\end{array}$ \\
\hline 5 & 30,5 & $20-32$ & $\begin{array}{c}\text { Sedikit } \\
\text { Panas }\end{array}$ \\
\hline
\end{tabular}

Berdasarkan tabel diatas pengaruh suhu udara terhadap tingkat kenyamanan, diketahui bahwa suhu minimal dengan ratarata $29,3^{\circ} \mathrm{C}$ dan suhu maksimal $30,5^{\circ} \mathrm{C}$ memberikan jumlah ketidak-nyamanan jauh lebih tinggi dari pada tingkat kualitas udara. Hal ini disebabkan karena saat istirahat untuk makan dan minum, pengunjungsusah berkonsentrasi dalam melakukan aktivitas. Selain itu dalam kondisi udara panas memaksa tubuh mengeluarkan keringat berakomodasi maksimum, sehingga dapat menimbulkan rasa gerah, panas dan sesak yang dapat menimbulkan pusing dan tidak nyaman.

\section{Analisis Data Jumlah Ketidaknyamanan}

Pengujian perbandingan merupakan pengujian beda tiga rata-rata atau lebih dengan dua faktor yang berpengaruh ketidak-nyamanan dan pengaruh interaksi ataupun respon dari pengunjung antara kedua faktor tersebut diperhitungkan. Sebelum dilakukan perhitungan perbandingan. Dan dilakukan terlebih dahulu uji kenormalan data. Dan didapat bahwa data yang diuji sangat normal, karena dalam penelitian ini tidak mengukur tingkat stress kerja ataupun error kerja.

\section{SIMPULAN}

Dalam lingkungan kerja fisik terdapat faktor eksternal dan faktor internalyang mempengaruhi aktivitas pengunjung dan karyawan kantin. Faktor eksternal seperti, suhu udara, pencahayaan, bau-bauan, getaran, warna, asap rokok, dan udara yang kotor. Sedangkan factor internalnya yaitu motivasi kerja, pengalaman kerja, kelelahan kerja. Darianalisis tabel pengukuran yang dilakukan, didapat-kan bahwa faktor ketidaknyamanan dan faktor suhu udara panas menjadi perlakuan yang menimbulkan jumlah pengunjung merasa tidak nyaman. Hal ini disebabkan karena pada suhu udara yang panas, pengunjung mengalami ekskresi keringat yang pesat.

Penilaian faktor lingkungan kerja fisik berupa suhu udara,penerangan, getaran, asap rokok dan bau-bauan yang ada di bagian ruang chef burjo borneo telah dilakukan seoptimal mungkin sebagai upaya untuk mencegah ketidak-nyamanan.

\section{DAFTAR PUSTAKA}

Akbar, R. Purnomo Setiady, dan Usman, Husaini, M.Pd.,M.T., (2006). Pengantar Statistika. Edisi Kedua. Jakarta: Bumi Aksara

Alfabeta. Suharsaputra. (2012). Metode Penelitian: Kuantitatif, Kualitatif, dan Tindakan. Bandung: PT Refika Aditama. 
Arikunto, Suharsimi. (2010). Prosedur Penelitian: Suatu Pendekatan Praktik. $\left(14^{\text {th }}\right.$ ed) Jakarta: PT Rineka Cipta.

Darmawan, Deni. (2013). Metode Penelitian Kuantitatif. Bandung: PT Remaja

Ashrae. (1989). Handbook of Fundamental Chapter 8: Physiological Principles.

Diponegoro Mochtar. (2013). Faktor yang Berhubungan dengan Stress Kerja pada Pedagang Tradisional Pasar Daya Kota Makassar Tahun 2013: 1-11

Gage, N.L, Berliner, David C. (1998). Educational psychology. Boston: Houghton Industri Institut Teknologi Bandung.Jurnal Sistem Teknik Industri Volume 6, No. 3 Mifflin.

Noor, Juliansyah. (2011). Metodologi Penelitian: Skripsi, Tesis, Disertasi, dan Karya IImiah Jakarta: Prenada Media Group. Ravai dan

Refika Aditama. Sugiyono (2010). Metode Penelitian Bisnis. Bandung : Penerbit Alfabeta.

Rosdakarya. Ghozali, Imam. (2013). Aplikasi Analisis Multivariate dengan Program IBM SPSS21: Update PLS Regresi. $\left(7^{\text {th }}\right.$ ed) Semarang: Badan Penerbit Universitas.

Firman Adhi. Sedarmayanti. (2011). Membangun dan Mengembangkan Kepemimpinan serta Meningkatkan Kinerja untuk Meraih Keberhasilan. Bandung:

Sugiyono, (2012). Metode Penelitian Kombinsasi. Bandung : Alfabeta.

Sugiyono. (2013). Metode Penelitian Pendidikan: Pendekatan Kuantitatif, Kualitatif, R\&D. (16 ${ }^{\text {th }}$ ed) Bandung: CV

Sutrisno, Edy. (2010). Manajemen Sumber Daya Manusia. Jakarta: Kencana.

Sutrisno, Edy. (2012). Budaya Organisasi. Jakarta: Kencana.

Suwanto, H, dan Donni Juni Priansa. (2010). Manajemen SDM Dalam Organisasi Publik dan Bisnis. Bandung : Alfabeta.

Tarwaka, Solichul HA dan Lilik Sudiajeng. (2004). Ergonomi untuk Kesehatan Kerja dan Produktivitas. Surakarta: Uniba Press. Temperatur Ruang Terhadap Kemampuan Kognitif. Skripsi Sarjana Universitas Andalas, Indonesia. 